\title{
Using SBaS Technology for Multi-Pass Series of Radar Images Processing
}

\author{
Olga L. Giniyatullina and Leonid S. Mikov* \\ Institute of Computational Techologies of SB RAS \\ 21 Rukavishnikova, Kemerovo, 650025, Russia
}

Received 23.04.2015, received in revised form 28.06.2015, accepted 06.09.2015

\begin{abstract}
The paper deals with the processing of radar images obtained by multi-pass shooting of the same area. It is proposed to use the Small Baselines Subset (SBaS) method to assess and reveal the dynamics of earth surface displacements in mining areas using vertical displacement maps. The method was tested on Cosmo-SkyMed radar data of the cities territory like Leninsk-Kuznetsky, Polysayevo and Belovo for the period from 2011 to 2014. The results of our survey, which helped to identify areas of subsidence and uplift of the earth's surface in these areas and the average rate of vertical displacement changes are adducer.
\end{abstract}

Keywords: radar data, radar interferometry, small baseline subset, Earth's surface displacement maps.

DOI: $10.17516 / 1999-494 X-2015-8-6-755-762$.

\section{Использование технологии SBaS \\ для обработки многопроходной серии \\ радарных изображений}

\author{
О.Л. Гиниятуллина, Л.С. Миков \\ Институт вычислительных технологий СО РАН \\ Кемеровский филиал \\ Россия, 650025, Кемерово, ул. Рукавишникова, 21
}

В статье рассматриваются вопросы обработки радарных изображений, полученных в результате многопроходной съемки одного и того же участка местности. Предлагается использование метода интерферометрии малых базовых линий (SBaS) для оценки и выявления динамики смещений земной поверхности в горнодобывающих районах с помощью построенных карт вертикальных смещений. Метод опробован на радарных данных со спутника Cosmo-SkyMed, покрывающих территорию городов Ленинска-Кузнецикого, Польсаево, Белово за период с 2011 по 2014 г. Приводятся результаты исследования,

(c) Siberian Federal University. All rights reserved

* Corresponding author E-mail address: skiporol@mail.ru, mikov@ict.sbras.ru 
которые позволили определить зоны оседания и поднятия земной поверхности в этих районах, а также выявить среднюю скорость изменения вертикальных смещений в мм/ год.

Ключевые слова: радарные данные, радарная интерферометрия, интерферометрия малых базовых линий, карты смещения земной поверхности.

\section{1. Введение}

Проблема оценки характера изменения земной поверхности становится актуальной в условиях усиленного развития урбанизированных территорий. Особенно важное значение приобретает мониторинг земной поверхности для территорий с активной добычей полезных ископаемых. В настоящее время для регулярного отслеживания динамики изменения уровня земной поверхности на обширных территориях применяются данные радиолокационной съемки. Сегодня радарные данные используются для решения широкого круга задач, в том числе:

- создание и обновление топографических карт;

- всепогодное наблюдение за природными и антропогенными катастрофами;

- оценка сейсмической опасности, прогнозирование землетрясений, извержений вулканов;

- создание цифровых моделей рельефа (ЦМР) и цифровых моделей местности (ЦММ);

- высокоточное наблюдение за состоянием инфраструктурных сетей (трубопроводы, железные дороги, телекоммуникации).

Радиолокационная съемка позволяет получать дополнительную информацию о состоянии поверхности и объектов наряду с данными оптического диапазона и может служить источником уникальной информации, получаемой либо только по радарным данным, либо по наземным измерениям [1].

В основе решения таких задач лежит обработка радарных изображений. Классическим методом обработки радарных данных является метод радарной дифференциальной интерферометрии (DInSAR). Данный метод активно развивается на протяжении последних 20 лет и базируется на измерениях разностей фаз эхосигналов от пространственно разнесенных точек при съемках одного и того же участка местности одноантенной радиолокационной системой с повторяющихся орбит носителя (с помощью интерферометра с мягкой базой) [2]. Как правило, в этом методе используют два радарных изображения (интерферометрическая пара), полученных в разное время, что позволяет выявить любые изменения земной поверхности, произошедшие за время между съемками.

Ряд авторов в своих работах [3-6] применяют данный метод для определения деформаций земной поверхности, возникающих при добыче полезных ископаемых. Однако метод DInSAR не позволяет выявить динамику изменения поверхности за длительный период времени по двум радарным изображениям. Это связано с потерей когерентности между сигналами, отраженными от одного и того же участка поверхности, на повторных снимках. Данный эффект называется декоррелящией. [7]. В связи с этим развитие метода DInSAR привело к появлению двух новых методов - метода устойчивых отражателей (PS) и метода интерферометрии малых базовых линий $(\mathrm{SBaS})$, которые позволяют проводить обработку не двух, а сразу серии радарных изображений. В статье мы рассмотрим последний из них. 


\section{2. Метод малых базовых линий}

Метод малых базовых линий (в англоязычной литературе - Small Baseline Subset, $\mathrm{SBaS}[8])$ позволяет регистрировать деформации земной поверхности и анализировать их пространственно-временные характеристики [9]. Идея метода заключается в поиске таких отражающих площадок, в которых влияние шумов минимально. Для таких пикселей производится разделение фазы, связанной с деформациями и фазовыми смещениями, выражаемыми атмосферными и ЦМР-артефактами. В частности, погрешности в ЦМР создают фазовые смещения, прямо пропорциональные перпендикулярной базовой линии. Для атмосферных помех принимается, что они плавно меняются в пространстве, но быстро - во времени. На этой основе вклад атмосферы и ошибок в ЦМР устанавливается и устраняется, что позволяет выделить составляющую, связанную со смещением площадок во времени.

Пусть имеется набор из $\mathrm{N}+1$ интерферометрических снимков одного и того же участка поверхности, сделанных в моменты времени t0, t1, ...tN. Будем считать, что уже выполнена процедура корегистрации относительно выбранного базового снимка, т.е. значения фазы и амплитуды на всех снимках проинтерполированы на одну и ту же сетку точек в системе координат выбранного мастера-снимка [10].

Вначале из полного набора снимков рассчитывается М интерферограмм, для которых выбирают пары снимков с наименьшей декорреляцией. Для этого используют пары снимков с наименьшей пространственной и временной базовой линией и с наименьшим сдвигом по частоте между доплеровскими центроидами (принцип расчета центроида см. в [11]). Далее формируются новые группы близких снимков и, таким образом, весь набор снимков оказывается разделенным на несколько групп, имеющих близкие характеристики. Данные по этим группам надо будет в дальнейшем объединить, чтобы оценить изменение смещений во времени.

Поскольку каждая парная интерферограмма представляет смещения по модулю $2 \pi$ (так называемая свернутая фаза), проводится развертка фазы с тем, чтобы получить полное смещение в направлении на спутник. При проведении развертки чаще всего сначала применяют алгоритмы «минимальной стоимости», а затем алгоритм «растущих подобластей». Первый алгоритм развертывает фазу в областях с хорошей корреляцией, а второй соединяет эти области, т.е. выполняет развертку в областях с низким отношением сигнал/шум.

\section{3. Исходные данные и район исследования}

Для апробации рассмотренного метода был выбран район размером 40х40 км в центральной части Кемеровской области, включающий территории городов Полысаево, Белово, Ленинск-Кузнецкий, характеризующиеся высокой техногенной нагрузкой. На исследуемой территории находится несколько крупных горнопромышленных предприятий. Выбранный регион был многократно отснят космическим аппаратом с синтезированной апертурой антенны COSMO-SkyMed. Это позволило сформировать набор радарных изображений высокого разрешения (3 м/пиксель) за период с 2011 по 2014 г. Список дат исходных изображений для обработки приведен в табл. 1.

Для выявления динамики и средней скорости изменения вертикальных смещений земной поверхности в исследуемом районе использовали 13 радарных снимков. При по-

$$
-757-
$$


Таблица 1. Список дат исходных радарных изображений

\begin{tabular}{|c|c|c|c|}
\hline \multicolumn{4}{|c|}{ Снимки Cosmo-SkyMed } \\
\hline $\mathbf{2 0 1 1}$ & $\mathbf{2 0 1 2}$ & $\mathbf{2 0 1 3}$ & $\mathbf{2 0 1 4}$ \\
\hline $10-08-2011$ & $15-07-2012$ & $16-06-2013$ & $11-06-2014$ \\
\hline $14-08-2011$ & $23-07-2012$ & $24-06-2013$ & $19-06-2014$ \\
\hline $22-08-2011$ & & $18-07-2013$ & $27-06-2014$ \\
\hline & & & $06-08-2014$ \\
\hline & & & $22-08-2014$ \\
\hline
\end{tabular}

строении карты вертикальных смещений на данный район выполнялся следующий граф обработки: автоматическая корегистрация, расчет интерферограммы, синтез фазы рельефа, вычитание фазы рельефа из интерферограммы, фильтрация дифференциальной интерферограммы, расчет когерентности, развертка фазы; набор точек с известными координатами и высотами для коррекции орбитальных параметров; расчет скорректированных дифференциальных интерферограмм и развернутых фаз; инверсия полученных перекрестных во времени развернутых фаз по методике SBaS с восстановлением последовательной во времени истории смещений [12]. При этом в итоге также восстанавливается хронология смещений от первого снимка цепочки до последнего. Для получения дифференциальных интерферограмм использовалась модель SRTM, довольно точно характеризующая рельеф исследуемого района. Вся обработка производилась в программном комплексе SARscape 5.1.

\section{4. Результаты}

С помощью метода $\mathrm{SBaS}$ была построена векторная карта вертикальных смещений земной поверхности (рис. 1) в формате KML, содержащая 90592 точки с когерентностью выше заданного порога (в работе использовался порог когерентности, равный 0,1 ).

Точки красного цвета соответствуют положительным вертикальным смещениям - поднятиям, синие - отрицательным вертикальным смещениям - оседаниям. Точки светло-зеленого цвета - стабильные точки без изменений. Каждая точка на карте имеет ряд атрибутов, таких как средняя скорость изменения вертикальных смещений в мм/год; значение когерентности; координаты; значение вертикальных смещений в каждый момент съемки (рис. 2).

В результате установлено, что в северной части исследуемого региона, в районе города Ленинска-Кузнецкого в течение 4 лет наблюдаются оседания земной поверхности со средней скоростью 16 мм/год (рис. 3-4).

В южной же части, в районе г. Белово, наоборот, регистрируются поднятия земной поверхности со средней скоростью 19 мм/год. (рис. 5-6).

Все эти смещения связаны с интенсивной добычей угля в этих районах. Кроме того, данные районы являются сейсмоопасными, за год в Кузбассе происходит более десяти тысяч геодинамических событий как природного, так и техногенного характера (промышленные взрывы). Отдельно отметим, что 19 июня 2013 и 11 августа 2014 г. в Беловском районе произошло два землетрясения с магнитудами 5,3 и 3,4 соответственно. 


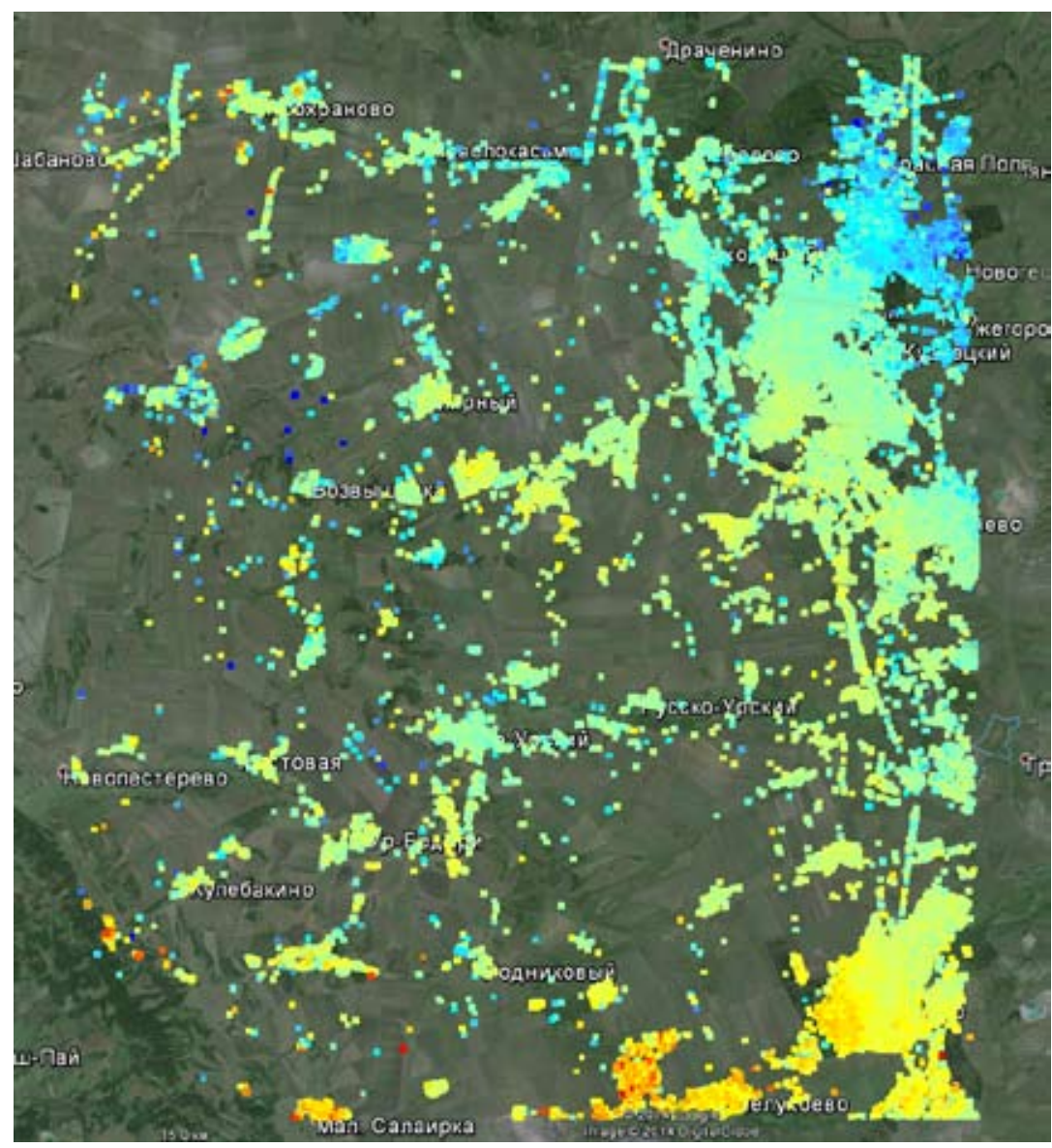

Рис. 1

\section{5. Выводы}

Обработка многопроходной серии радарных изображений методом $\mathrm{SBaS}$ за 1108 дней позволила произвести площадную оценку вертикальных смещений земной поверхности, выявить участки оседания и поднятия. Полученные результаты могут помочь в оценке влияния горного производства на окружающую среду, а также показывают целесообразность осуществления мониторинга с применением технологии SBaS в сейсмоопасных регионах с высокой техногенной нагрузкой. Обработка серии радарных изображений может служить основой для последующей разработки природоохранных мероприятий и геоинформационных систем мониторинга деформационных процессов земной поверхности. 
Point Position : [Latitude : 54.34 ] [Longitude : 85.95 ]

Point Height : [209.25]

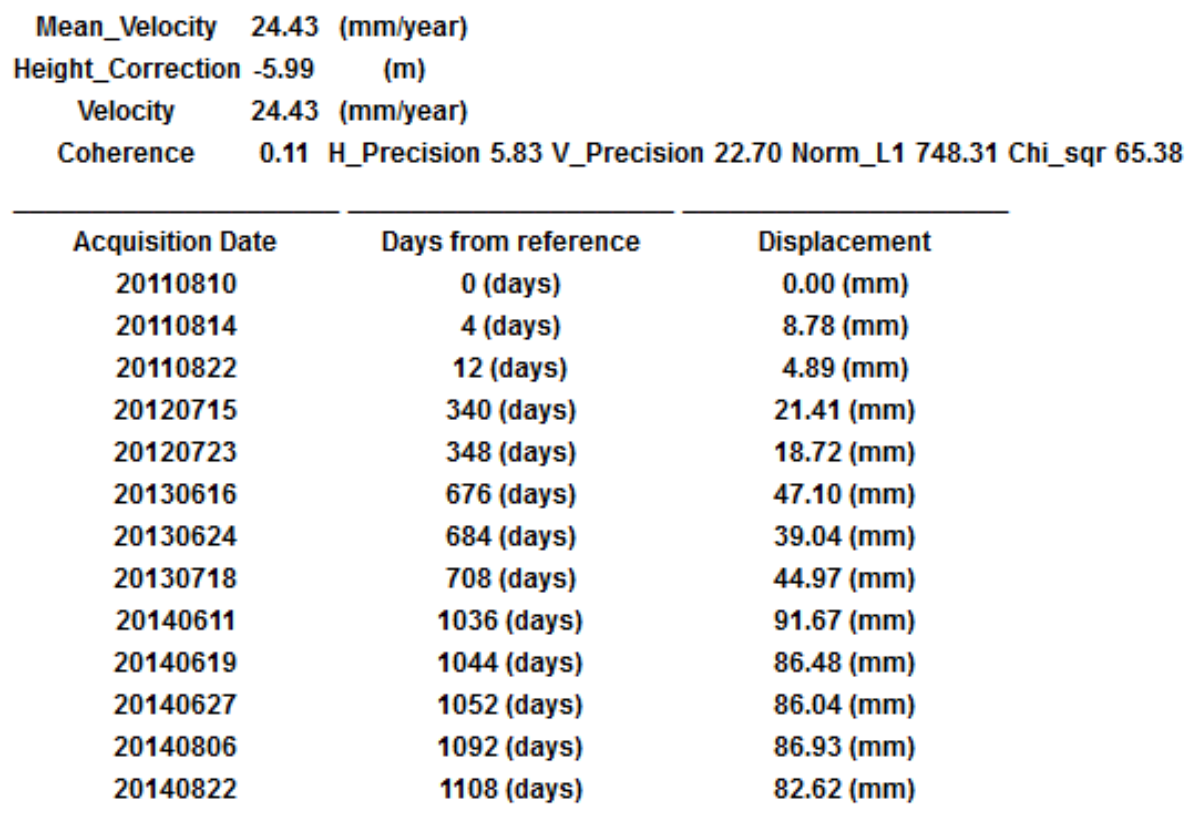

Рис. 2

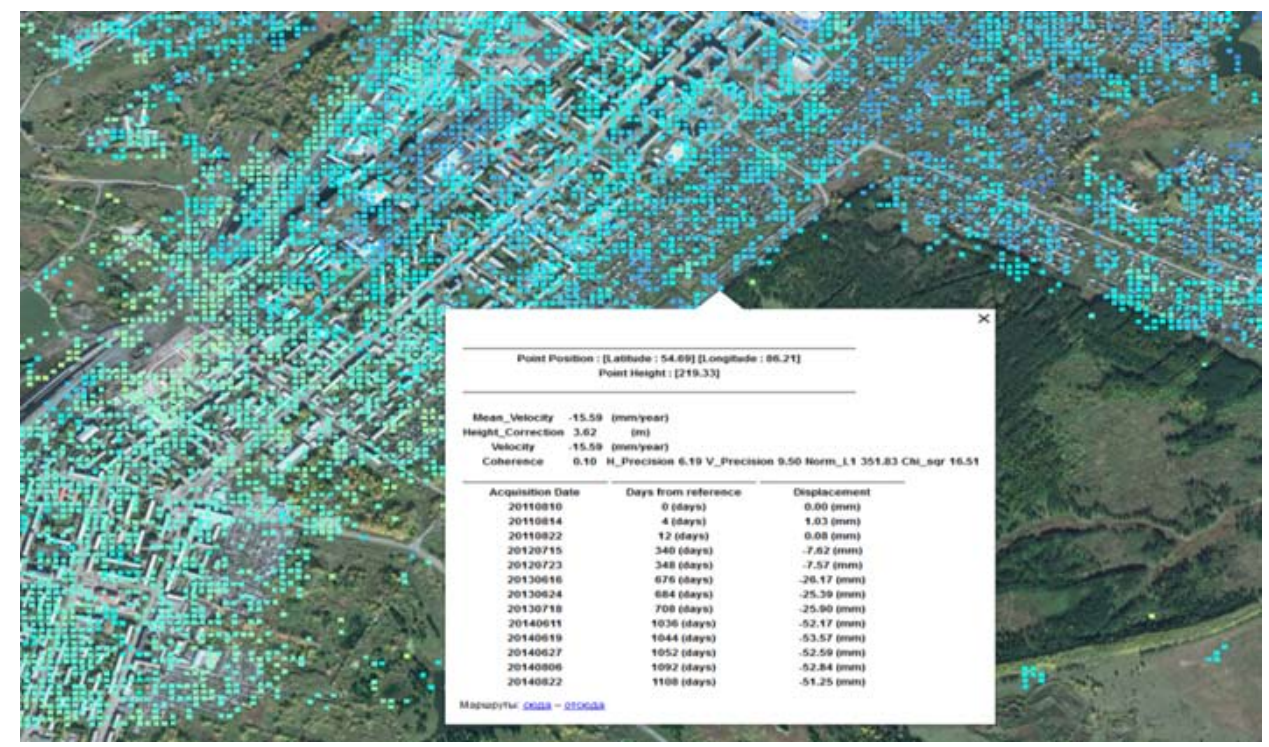

Рис. 3 


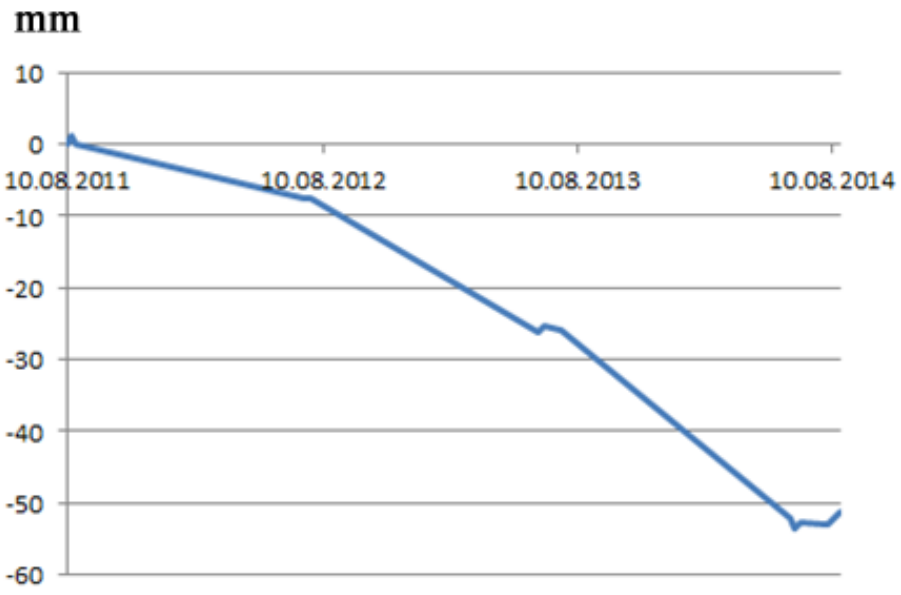

Рис. 4

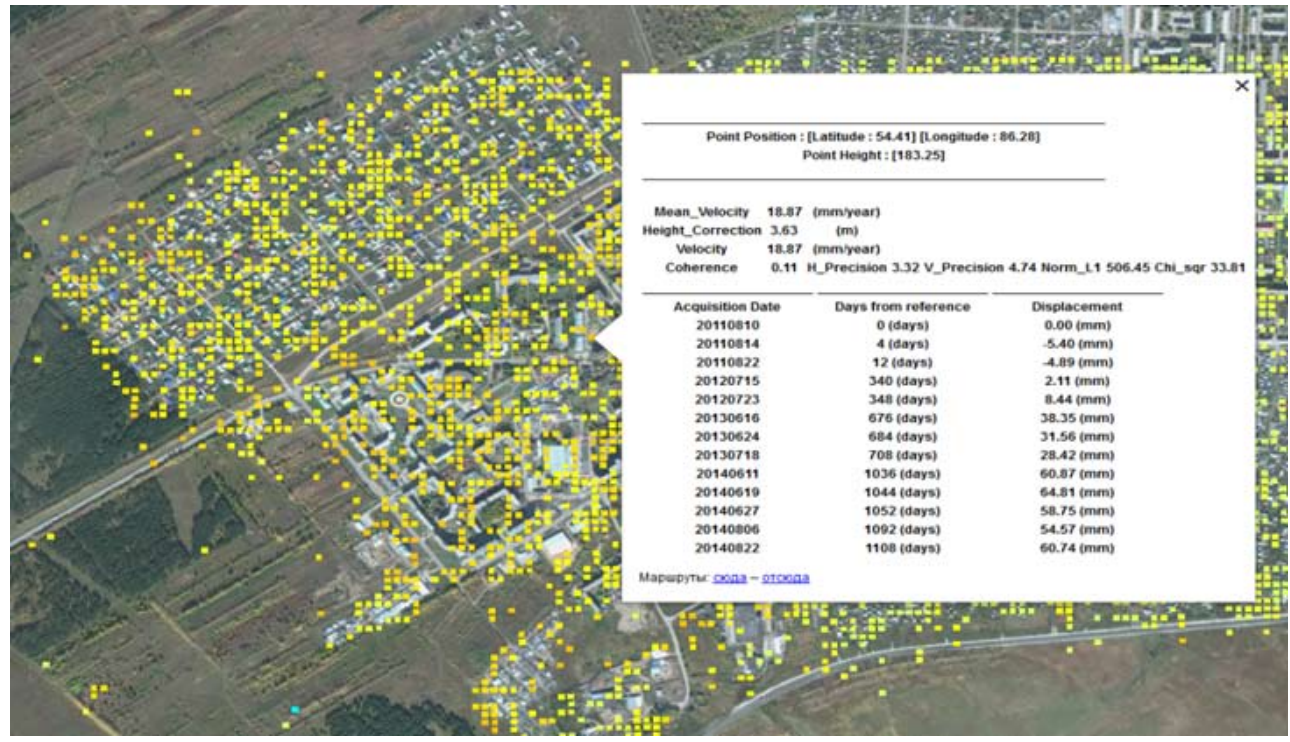

Рис. 5 


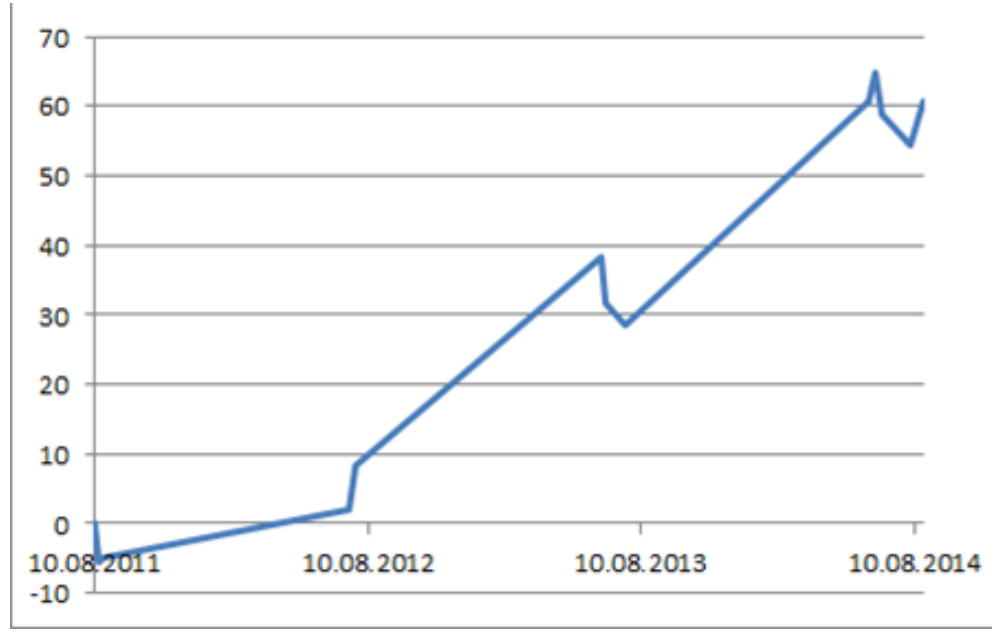

Рис. 6

\section{Список литературы}

[1] Обработка радарных данных - Совзонд [Электронный ресурс]. - URL: http://sovzond.ru/ services/radar-data-processing/ (дата обращения: 20.04.2015)

[2] Rosen PA, Hensley S, Joughin IR, Li FK, Madsen SN, Rodriguez E //Proc IEEE 88(3). 2000. P. 333-382.

[3] Мусихин В.В Дис. ... канд. техн. наук. Пермь. 2012. С. 146.

[4] Горский Д.А., Хоменков К.А. // Геоматика. 2012. № 4. С. 65-76.

[5] Жантаев Ж.Ш., Фремид А.Г.// Геоматика. 2012. № 1. С. 61-72.

[6] Черкасов В.А., Баранов Ю.Б. // Геоматика. 2012. № 4. С. 52-60.

[7] Zebker, H. A. // IEEE trans. geosci. remote sensing. 1992. Vol. 30. P. 950-959.

[8] Berardino, P.// IEEE transact. geoscience and remote sensing. 2002. Vol. 40. №. 11. P. 23752383.

[9] Lanari, R.// Pure appl. geophy. 2007. Vol. 164. P. 637-661.

[10] Дмитриев П.Н. Дис. ...канд. физ.-мат. наук. М., 2013. С. 124.

[11] Franceschetti, G.// CRC press, 1999.

[12] Кантемиров Ю.Н. // Геоматика. 2012. № 1. С. 22-26. 